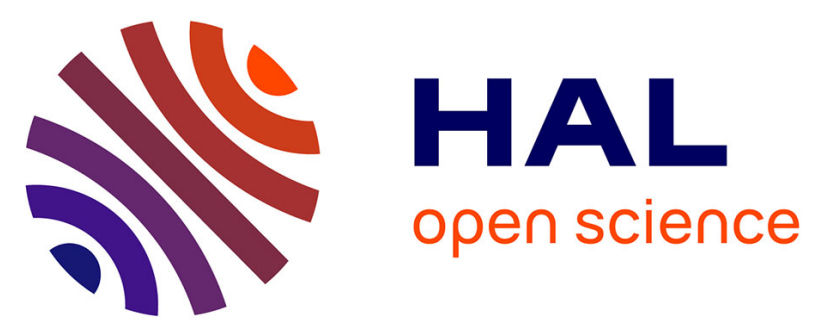

\title{
C-C Bond Formation of Benzyl Alcohols and Alkynes Using a Catalytic Amount of KO t Bu: Unusual Regioselectivity through a Radical Mechanism
}

Amit Kumar, Trevor Janes, Subrata Chakraborty, Prosenjit Daw, Niklas von Wolff, Raanan Carmieli, Yael Diskin-Posner, David Milstein

\section{To cite this version:}

Amit Kumar, Trevor Janes, Subrata Chakraborty, Prosenjit Daw, Niklas von Wolff, et al.. C-C Bond Formation of Benzyl Alcohols and Alkynes Using a Catalytic Amount of KO t Bu: Unusual Regioselectivity through a Radical Mechanism. Angewandte Chemie International Edition, 2019, 58 (11), pp.3373-3377. 10.1002/anie.201812687 . hal-03017842

\section{HAL Id: hal-03017842 https://hal.science/hal-03017842}

Submitted on 8 Dec 2020

HAL is a multi-disciplinary open access archive for the deposit and dissemination of scientific research documents, whether they are published or not. The documents may come from teaching and research institutions in France or abroad, or from public or private research centers.
L'archive ouverte pluridisciplinaire $\mathbf{H A L}$, est destinée au dépôt et à la diffusion de documents scientifiques de niveau recherche, publiés ou non, émanant des établissements d'enseignement et de recherche français ou étrangers, des laboratoires publics ou privés. 


\title{
C-C Bond Formation of Benzyl Alcohols and Alkynes using Catalytic Amount of KO'Bu: Unusual Regioselectivity via a Radical Mechanism
}

\author{
Amit Kumar, ${ }^{\dagger}$ Trevor Janes, ${ }^{\dagger}$ Subrata Chakraborty, ${ }^{\dagger}$ Prosenjit Daw, ${ }^{\dagger}$ Niklas von Wolff, ${ }^{\dagger}$ Raanan \\ Carmieli, ${ }^{\ddagger}$ Yael Diskin-Posner ${ }^{\ddagger}$ and David Milstein. ${ }^{\dagger *}$
}

\begin{abstract}
We report the $\mathrm{C}-\mathrm{C}$ bond-forming reaction of benzyl alcohols and alkynes using a catalytic amount of KO'Bu to form $\alpha$-alkylated ketones in which the $\mathrm{C}=\mathrm{O}$ group is located on the side derived from the alcohol, a reaction that has not been reported yet in the peerreviewed literature. The reaction proceeds under thermal condition $\left(125^{\circ} \mathrm{C}\right)$ and produces no waste, making the reaction highly atomefficient, environmentally benign and sustainable. Based on our mechanistic investigations we propose that the reaction proceeds through radical pathways.
\end{abstract}

Transition-metal-catalyzed C-C bond formation is one of the most powerful tools for the synthesis of organic compounds. ${ }^{[1]}$ There has been a tremendous amount of development made in this area offering efficient catalysts for challenging transformations and enriching our mechanistic understanding. Nevertheless, transition-metal catalysts have several limitations such as toxicity, complex handling techniques for many transitionmetal catalysts, low abundance and high cost of noble transitionmetals. Therefore, the replacement of transition-metal catalysts with transition-metal-free catalysts is of much interest. In fact, significant progress has been made towards the development of $\mathrm{C}-\mathrm{C}$ bond forming reactions free from transition metals. ${ }^{[2]}$ Several $\mathrm{C}-\mathrm{C}$ coupling reactions have also been reported using stoichiometric amounts (or more) of KOtBu. ${ }^{[2]}$ Recently Stoltz and Grubbs have reported a transition-metal-free silylation of $\mathrm{C}-\mathrm{H}$ bonds of aromatic heterocycles catalyzed by $\mathrm{KO}^{\mathrm{t}} \mathrm{Bu} .{ }^{[3]}$

Among several $\mathrm{C}-\mathrm{C}$ bond forming reactions, formation of $\alpha$ alkylated ketones is important because of their interesting pharmacological and physiological properties. ${ }^{[4]}$ In particular, dihydrochalcones (a category of a-alkylated ketones) are found in natural products such as Naringin dihydrochalcone and Aspalathin and are used as artificial sweeteners and antioxidants. ${ }^{[4 f, 4 g]} \mathrm{A}$ conventional route to the synthesis of $\alpha$ alkylated ketones involves the reaction of an enolate with an alkyl halide in presence of at least a stoichiometric amount of base, thus generating a stoichiometric amount of waste. Dihydrochalcones are also synthesized by the transiton-metal catalyzed hydrogenation of chalcones (Scheme 1a). ${ }^{[5]}$ Much attention has been paid to the C-alkylation of ketones using alcohols as alkylating agents and several catalysts based on transition metals such as iridium, ruthenium, palladium, manganese, cobalt, iron and copper have been reported for this transformation (Scheme 1b). ${ }^{[6]}$ In most of the cases at least a stoichiometric amount of base is used as additive. Despite significant progress, this reaction is limited to ketones as the

[*] Dr. A. Kumar, Dr. T. Janes, Dr. S. Chakraborty, Dr. P. Daw, Dr. N. von Wolff, Prof. D. Milstein

Department of Organic Chemistry, Weizmann Institute of Institution Rehovot, Israel, 76100

E-mail: david.milstein@weizmann.ac.il

Dr. R. Carmieli, Dr. Y. Diskin-Posner

Chemical Research Support, Weizmann Institute of Science

Rehovot, Israel, 76100

Supporting information for this article is given via a link at the end of the document. starting materials. For wide synthetic application, it would be attractive to use other substrates instead of ketones for the production of $\alpha$-alkylated ketones using alcohol as the alkylating agent.

Recently, the C-C bond-forming reaction of alkynes with alcohols using a combination of transition-metal-catalysts and water (or without water) to form a-alkylated ketones has been reported (Scheme 1c). ${ }^{[7]}$ The reaction proceeds via the Markovnikov hydration of alkynes to form methyl ketones followed by the C-alkylation of methyl ketones using alcohols. The obtained product contains the $\mathrm{C}=\mathrm{O}$ group on the side derived from the alkyne. Although this reaction is atom-efficient, the development of a catalyst that is free from transition-metals and expensive ligands, and avoids waste generation, would make the overall process simpler, less-expensive, environmentally-benign and sustainable. Herein, we present the $\mathrm{C}-\mathrm{C}$ bond forming reaction of benzyl alcohols with alkynes using a catalytic amount of an inexpensive and commercially available base - KO'Bu (Scheme 1d). The obtained products, a-alkylated ketones, in particular dihydrochalcones, uniquely contain the $\mathrm{C}=\mathrm{O}$ group on the side derived from the alcohol; a reaction exhibiting such unusual regioselectivity has not been reported in the peerreviewed literature.

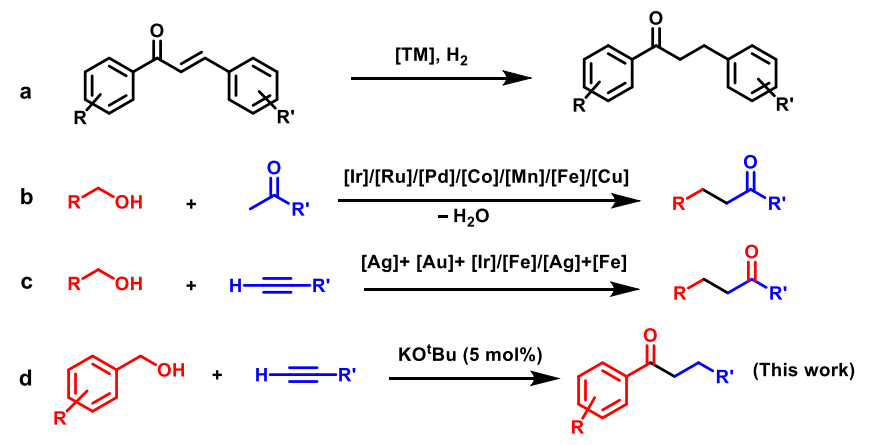

Scheme 1. (a) Synthesis of dihydrochalcones by the transition-metal-catalysed hydrogenation of chalcones (b) Transition-metal catalyzed C-alkylation of ketones; (c) transition-metal catalyzed reaction of alcohols and alkynes and (d) the reaction reported in this work.

We discovered that refluxing a toluene solution of benzyl alcohol $(0.5 \mathrm{mmol})$ and phenyl acetylene $(0.5 \mathrm{mmol})$ at $125^{\circ} \mathrm{C}$ for $24 \mathrm{~h}$ in the presence of KO'Bu (5 mol\%) results in the formation of 1,3-diphenylpropan-1-one (1) in $80 \%$ yield. The reaction also proceeds, although with relatively lower yields, with other potassium bases such as $\mathrm{KH}, \mathrm{KOH}$ and KHMDS (Table 1, entries 2-4). However, no product formation was observed when the weaker base $\mathrm{K}_{2} \mathrm{CO}_{3}$ was used. Poor yield of the product was obtained when $\mathrm{NaO} \mathrm{Bu}^{\mathrm{B}}$ and $\mathrm{NaOH}$ (entries 6-7) were used, suggesting that potassium ion is important for the catalysis. Lowering the reaction temperature to $55^{\circ} \mathrm{C}$ completely thwarted the reaction, whereas increasing the temperature to $135^{\circ} \mathrm{C}$ slightly lowered the yield (entries 8-9). We also observed that use of non-polar solvents such as toluene or methyl cyclohexane resulted in better product yield compared to polar solvents such as THF, 1,4-dioxane or acetonitrile (entries 10-13). Using DMF as a solvent also resulted in lower yield of 1 (entry 14); styryl ether (I, vide infra, $55 \%$ yield) was observed as the major product. DMF 
in presence of $\mathrm{KO}^{\mathrm{t}} \mathrm{Bu}$ can be deprotonated to form $\mathrm{CONMe}_{2}$ anion that can be involved in the electron transfer reactions. ${ }^{[8]}$ Finally, no conversion of reactants was observed when the reaction was performed in the absence of base (entry 15).

Table 1: Optimization of the reaction of benzyl alcohol and phenyl acetylene. ${ }^{\text {a }}$

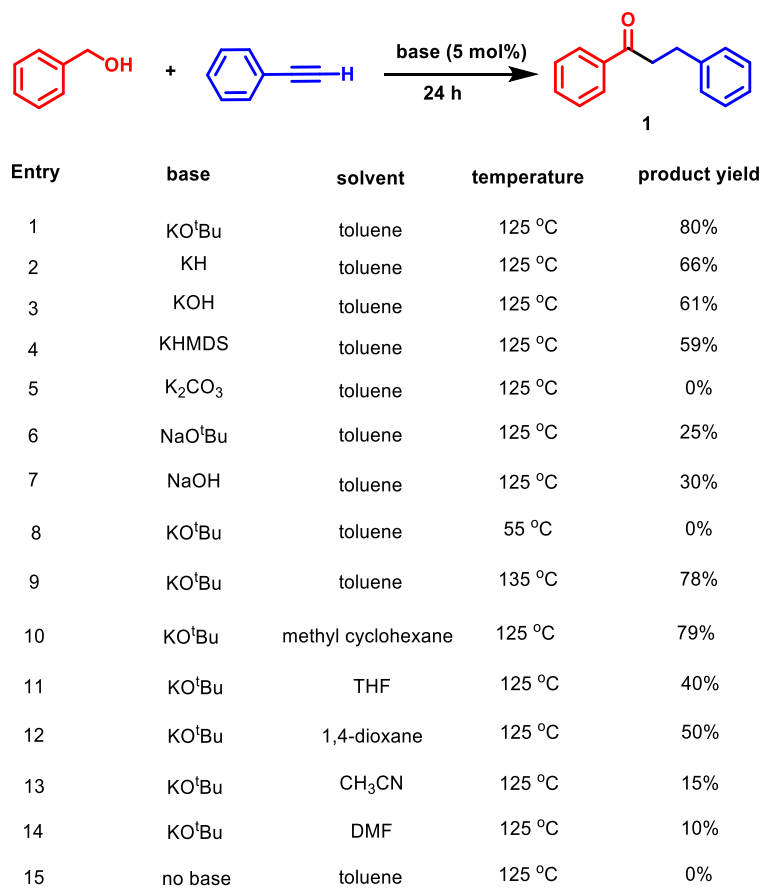

aConditions: KOtBu $(0.025 \mathrm{mmol})$, benzyl alcohol $(0.5 \mathrm{mmol})$, phenyl acetylene $(0.5 \mathrm{mmol})$, solvent $(1 \mathrm{~mL}), 24 \mathrm{~h}$ (reaction time), temperature: $125^{\circ} \mathrm{C}$. The yield of the product (1) was determined by $1 \mathrm{H}$ NMR spectroscopy using mesitylene as an internal standard.

Table 2: Substrate scope for the formation of a-alkylated ketones. ${ }^{a}$
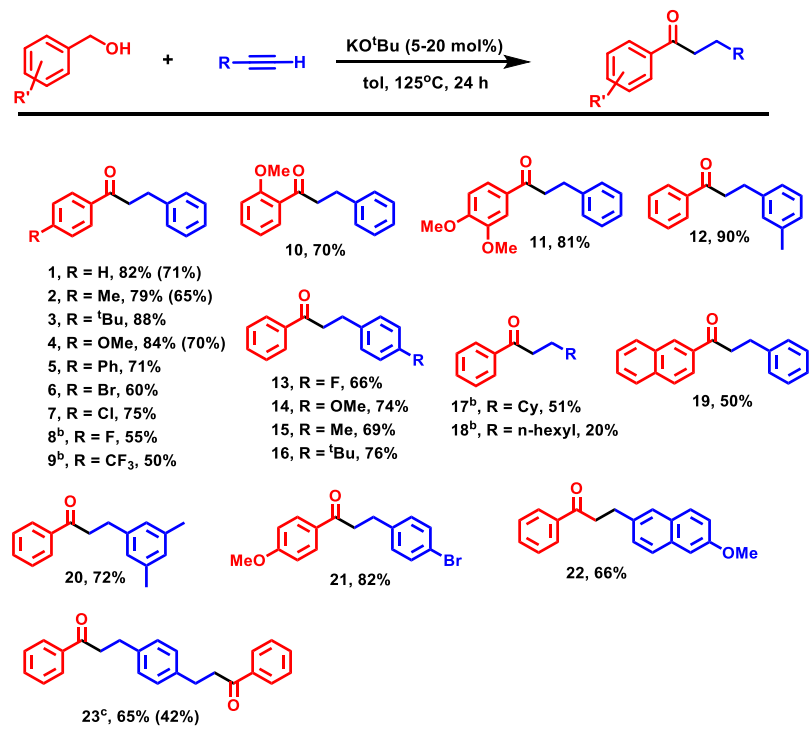

aConditions: KO'Bu (0.05 mmol), alcohol (1 mmol), alkyne (1 mmol), toluene (2 $\mathrm{mL}), 24 \mathrm{~h}, 125^{\circ} \mathrm{C}$. ${ }^{b} \mathrm{KOtBu}(0.2 \mathrm{mmol}) .{ }^{\mathrm{c}} \mathrm{KO} \mathrm{B}^{\mathrm{B} u}(0.05 \mathrm{mmol})$, benzyl alcohol (1 $\mathrm{mmol}), 1,4$-diethynylbenzene $(0.5 \mathrm{mmol})$, Products were confirmed by GC-MS. The yields of the products were determined by ${ }^{1} \mathrm{H}$ NMR spectroscopy using mesitylene as an internal standard. Numbers in parentheses represent the isolated yields.

We next explored the substrate scope of this reaction. As shown in Table 2, the reaction works well with various substituted benzyl alcohols and substituted phenyl acetylenes. Electrondonating substituents on the benzyl alcohol such as methoxy and $t$-Bu groups ( 3 and $\mathbf{4}$ ) gave better yields relative to the electron withdrawing substituents fluoride and $\mathrm{CF}_{3}(8$ and 9 ). Product 2 was also isolated on a gram scale $(1.45 \mathrm{~g}, 65 \%$ yield). The structure of product 4 was confirmed by single crystal X-ray diffraction, proving that the carbonyl group is on the side derived from the alcohol (SI, Figure S11). It is worth noting that the only transformation with the regioselectivity of this type was reported in a recent patent ${ }^{[9]}$ using an iridium catalyst, and to the best of our knowledge it is unknown in the peer-reviewed literature. Only $20 \%$ of the ketone product (16) was observed when 1-octyne was used; dimerization of 1-octyne was detected as the major product by GC-MS. Heterocyclic alcohols and alkynes such as 3pyridinemethanol and furfuryl alcohol also resulted in poor yield of the corresponding ketone $(<20 \%$, see Table S2 in SI). Using an internal alkyne, diphenyl acetylene in place of phenyl acetylene, also did not result in any product formation, benzyl alcohol and diphenyl acetylene were recovered after the reaction (see Table $\mathrm{S} 2$, in $\mathrm{SI}$ ).

Reaction of 1-hexanol $(1 \mathrm{mmol})$ with phenyl acetylene $(1$ $\mathrm{mmol}$ ) using $10 \mathrm{~mol} \% \mathrm{KO}$ B Bu in toluene for $24 \mathrm{~h}$ at $125^{\circ} \mathrm{C}$ did not result in the formation of the expected ketone product; instead, addition of the alkoxide to phenyl acetylene took place forming a mixture of two geometrical isomers of 2-(hexyloxy)vinyl benzene in $1: 3$ ratio ( $65 \%$ overall isolated yield, Scheme 2$)$. This is similar to that reported by Kondo for alkyne functionalization using a phosphazane base $\mathrm{P}_{4}-t$-Bu as a catalyst. ${ }^{[10]}$

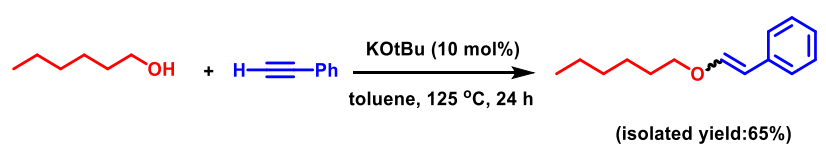

Scheme 2. Reaction of hexanol with phenyl acetylene catalyzed by KOtBu.

As the catalytic reaction of benzyl alcohols and alkynes using $\mathrm{KO}^{\prime} \mathrm{Bu}$ was unprecedented, we endeavored to understand the mechanism of this reaction. The influence of light or trace transition metals was ruled out by control experiments and ICPMS analysis (see $\mathrm{SI}$ ). As demonstrated earlier, potassium ion is important for catalysis as lower yields are obtained using the corresponding sodium bases (Table 1). Moreover, addition of 18Crown-6 $(10 \mathrm{~mol} \%)$ to the catalytic mixture decreased the product yield to $40 \%$, confirming the important role of the potassium ion in the catalysis, as also previously observed by Stoltz and Houk, and Wilden. ${ }^{[3 c, 11]}$

A possible mechanism for this transformation could proceed via a hydrogenation/dehydrogenation pathway; dehydrogenation of the alcohol to aldehyde followed by its coupling with the alkyne and then hydrogenation and rearrangement. However, formation of hydrogen during the reaction was not detected by GC or ${ }^{1} \mathrm{H}$ NMR spectroscopy. We also did not observe the formation of any aldehyde or styrene that might be formed via the transfer hydrogenation mechanism. Additionally, reaction of benzaldehyde with either styrene or phenyl acetylene in presence of $10 \mathrm{~mol} \% \mathrm{KO} \mathrm{B}^{\mathrm{t}} \mathrm{Bu}\left(125^{\circ} \mathrm{C}, 24 \mathrm{~h}\right)$ resulted in the formation of benzyl benzoate as the major product, most likely through the Tischenko mechanism, ${ }^{[12]}$ while styrene or phenyl acetylene were found to be mostly unreacted. This suggests that the reaction does not proceed through hydrogenation/dehydrogenation pathways.

We also ruled out the possibility of a mechanism where the coupling of alcohol and alkyne proceeds via the Markovnikov addition of water to the alkyne since the presence of molecular sieves in the reaction mixture did not affect the product yield. Also, the reaction proceeding via the Markovnikov addition of water to alkyne would result in a product where the $\mathrm{C}=\mathrm{O}$ group is located on the side of the alkyne derivative as previously reported. ${ }^{[7]}$ However in this case, as confirmed by the X-ray diffraction, the product contains the $\mathrm{C}=\mathrm{O}$ group on the side of alcohol $(\mathrm{SI}$, Figure S11).

Another pathway we considered involves reaction of benzyl alcohol and phenyl acetylene to give styryl ether I that undergoes a 1,2 -Wittig type rearrangement ${ }^{[13]}$ to give an allylic 
alcohol (II) which can isomerize to the ketone product 1 (Scheme 3). However, this possibility was ruled out since no conversion of the styryl ether (I) was obtained when refluxed in toluene in presence of $10 \mathrm{~mol} \% \mathrm{KO}{ }^{\mathrm{t}} \mathrm{Bu}$.

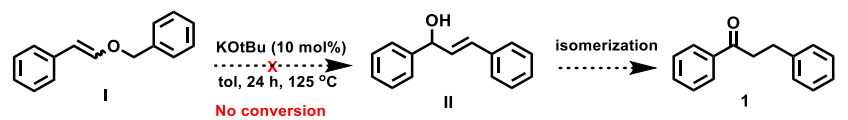

Scheme 3. Ruling out of the mechanism involving styryl ether intermediate.

Furthermore, we explored the possibility of a radical mechanism. Interestingly, addition of one equivalent of the radical scavengers TEMPO or galvinoxyl to the reaction mixture under the conditions of Table 1 , entry 1 , decreased the yield of the product to $40 \%$ and $0 \%$, respectively. Unfortunately, attempts to characterize any trapped radical were not successful. Interestingly, an EPR spectrum taken after 5 minutes of heating $\left(125^{\circ} \mathrm{C}\right)$ of benzyl alcohol and phenyl acetylene in the presence of $\mathrm{KO}^{\mathrm{t}} \mathrm{Bu}(10 \mathrm{~mol} \%)$ showed a signal suggesting a carbon-based radical (Figure 1). No EPR signal was detected by heating a toluene solution of benzyl alcohol and phenyl acetylene in the absence of $\mathrm{KO} B \mathrm{Bu}$ or by reacting benzyl alcohol, phenyl acetylene and $\mathrm{KO}^{\mathrm{t}} \mathrm{Bu}(10 \mathrm{~mol} \%$ in toluene) at room temperature. Control EPR experiments performed by reacting $\mathrm{KO}^{\mathrm{t}} \mathrm{Bu}(10 \mathrm{~mol} \%)$ and benzyl alcohol or $\mathrm{KO}^{\mathrm{t}} \mathrm{Bu}(10 \mathrm{~mol} \%)$ and phenyl acetylene in toluene $\left(125^{\circ} \mathrm{C}\right)$ also did not show the presence of any radical. This suggests that perhaps the role of $\mathrm{KO}^{\mathrm{t}} \mathrm{Bu}$ is to deprotonate the alcohol and that the radical is generated by interaction of the alkoxide with the alkyne. This is consistent with the observation of product formation, albeit in lower yields, with bases such as $\mathrm{KOH}$ and $\mathrm{KH}$ that are not known for exhibiting electron transfer reactivity under the catalytic conditions used here. Mechanisms where $\mathrm{KO}$ ' $\mathrm{Bu}$ or $\mathrm{KH}$ are not the radical source itself but assist in the generation of a radical source by reacting with an additive or substrate were proposed before. ${ }^{[2 b, 14]}$

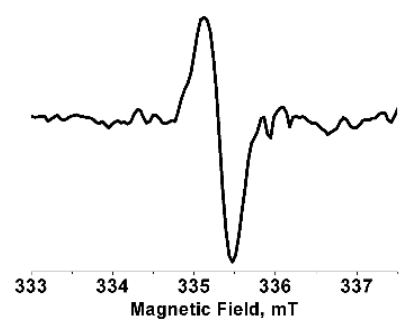

Figure 1. EPR spectrum upon heating a toluene solution of benzyl alcohol, phenyl acetylene and $\mathrm{KO}^{\mathrm{t}} \mathrm{Bu}$.

Additionally, cyclic voltammetry experiments (SI, Figures S3-S4) exhibited a high potential gap $\Delta \mathrm{E}=1.83 \mathrm{~V}$ between the first oxidation peak potential of a mixture of $\mathrm{PhCH}_{2} \mathrm{OH} / \mathrm{KO}{ }^{\mathrm{t}} \mathrm{Bu}(+0.58 \mathrm{~V})$ and the first reduction peak potential of phenyl acetylene $(-1.25 \mathrm{~V})$ excluding a fast outer sphere electron transfer, as also suggested by Jutand and Lei for the electron transfer between $\mathrm{KO}^{\mathrm{t}} \mathrm{Bu}$ and 1,10-phenanthroline. ${ }^{[15]}$

Based on these experiments we propose the following mechanism for the $\mathrm{C}-\mathrm{C}$ bond forming reaction of benzyl alcohols and alkynes (Scheme 4).

Initiation: We suggest that the first step is the deprotonation of benzyl alcohol by $\mathrm{KO}^{\mathrm{t}} \mathrm{Bu}$ to form $\mathrm{PhCH}_{2} \mathrm{OK}$. The catalytic reaction can get initiated by a Hydrogen Atom Transfer (HAT) from $\mathrm{PhCH}_{2} \mathrm{O}^{-}$to phenyl acetylene resulting in the formation of the radicals $\mathbf{A}$ and $\mathbf{A}^{\prime} \cdot{ }^{[16]}$ The transfer of a hydrogen radical from the benzylic position of the corresponding alkoxides has previously been proposed. ${ }^{[16 a, 17]}$ The transfer of a hydrogen radical to phenyl acetylene was also documented before.$^{[16 \mathrm{~b}]}$ Additionally, based on our DFT calculations at the M062X/6-31+G(d,p) level, $\Delta G$ for the HAT from $\mathrm{PhCH}_{2} \mathrm{O}^{-}$to phenyl acetylene was found to be $8.3 \mathrm{kcal}$ $\mathrm{mol}^{-1}$ suggesting that the process might be feasible under the reaction conditions used here. We suggest that the radical $\mathbf{A}^{\prime}$ generated in the initiation process gets consumed by its reaction with phenyl acetylene as the conversion of alkynes are greater than the conversion of benzyl alcohols (Table S1, SI). Additionally, ESI-MS experiment of the reaction mixture showed signals with a mass difference of 102 in the region of $\mathrm{m} / \mathrm{z} 491$ to 799 indicative of the formation of poly(phenyl acetylene), presumably from the reaction of A' with phenyl acetylene (see SI, Figure S10). Although all the reactions have been performed under nitrogen atmosphere using deoxygenated solvents, radical initiation via reaction of $\mathrm{KO} B \mathrm{Bu}$ with adventitious molecular oxygen is a possibility, and has been suggested by Houk and Stoltz based on DFT calculations. ${ }^{[3 c]}$ To explore this possibility, we carried out a catalytic experiment in presence of 200 or 2000 ppm of oxygen gas using the reaction conditions as described in Table 1, entry 1. After completion of the reaction, similar conversion of reactants and the similar product yield was observed as that observed without adding any external oxygen gas (see SI). However, when a reaction was performed using 1 bar of oxygen, no formation of 1 and almost no conversion of benzyl alcohol was observed. Based on these experimental evidences, it seems unlikely that molecular oxygen is involved in the reaction, and more detailed mechanistic investigation will be pursued in future communications.

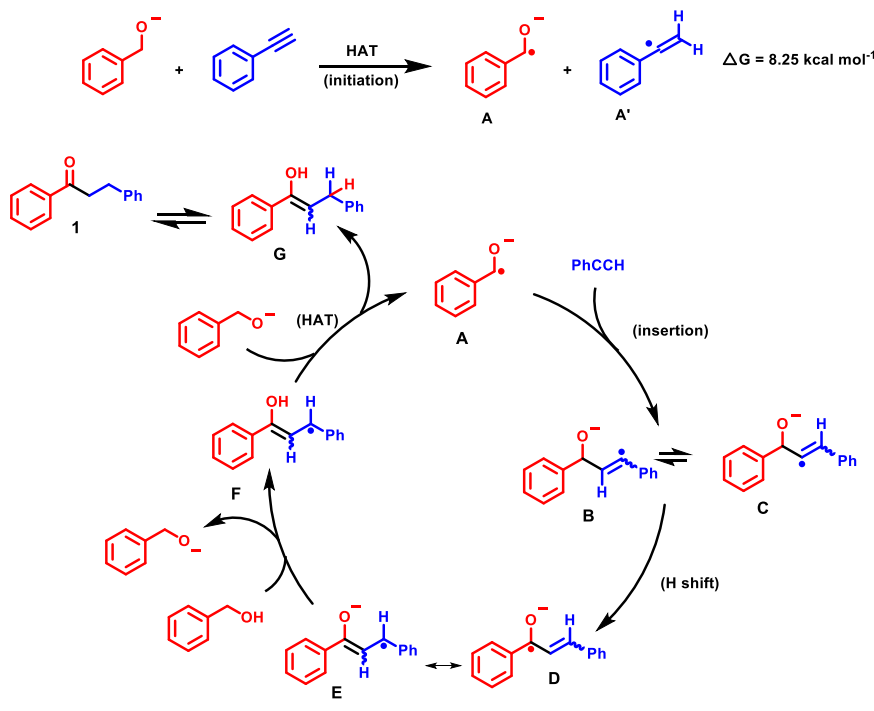

Scheme 4. Proposed mechanism for the reaction of benzyl alcohols and phenyl acetylene using a catalytic amount of base.

Radical chain catalytic cycle: The alkoxide radical $\mathbf{A}$ can insert into phenyl acetylene to form the radical intermediate $B, \Delta G$ for which was found to be $10.8 \mathrm{kcal} \mathrm{mol}^{-1}$. B can undergo a 1,2hydrogen shift to form the intermediate $\mathbf{C}\left(\Delta \mathrm{G}=6.8 \mathrm{kcal} \mathrm{mol}^{-1}\right)$. Intermediates $\mathbf{B}$ and $\mathbf{C}$ can convert to intermediate $\mathbf{D}$ via 1,3 and 1,2-hydrogen shifts, respectively, which is related to the radical $\mathbf{E}$ via resonance $\left(\Delta G, B\right.$ to $D=-57.7 \mathrm{kcal} \mathrm{mol}^{-1} \& \Delta G, C$ to $D=-64.5$ kcal mol $\left.{ }^{-1}\right)$. E can then be protonated by $\mathrm{PhCH}_{2} \mathrm{OH}$ to form the radical $\mathbf{F}$ and $\mathrm{PhCH}_{2} \mathrm{O}^{-}$anion $\left(\Delta \mathrm{G}=38.6 \mathrm{kcal} \mathrm{mol}^{-1}\right)$. $\mathrm{PhCH}_{2} \mathrm{O}^{-}$ anion can transfer a hydrogen radical (HAT) to $F$ to form the intermediate $\mathbf{G}$ and regenerate the intermediate $\mathbf{A}(\Delta \mathrm{G}=-22.7$ $\left.\mathrm{kcal} \mathrm{mol}{ }^{-1}\right)$. Upon tautomerization, $\mathbf{G}$ transforms to product $\mathbf{1}(\Delta \mathrm{G}$ $=-5.5 \mathrm{kcal} \mathrm{mol}^{-1}$ ). It is very likely that the reaction is driven by the highly favorable thermodynamics of the product formation as the $\Delta \mathrm{G}$ of the overall reaction was found to be $-36.5 \mathrm{kcal} \mathrm{mol}^{-1}$. It is worth noting that the values of $\Delta G$ presented here are only for the purpose of comparing the relative energy of the intermediates as potassium is excluded from the calculation for the sake of simplicity. We believe that the stability of radical intermediates such as $\mathbf{A}$ and $\mathbf{B}$ is critical for the catalysis since the reaction scope is limited to benzylic alcohols where the radicals are stabilized by resonance with the phenyl ring. Similarly, higher yields are obtained with phenyl acetylene compared to aliphatic alkynes where self-coupling of the alkyne is observed as the major product (18, Table 2, also see Table S1 in SI). 
To lend support for the hydrogen shifts as proposed in the mechanism, we performed experiments with deuterated substrates. Indeed, the reaction of $\mathrm{PhCCD}$ with $\mathrm{PhCH}_{2} \mathrm{OH}$, or $\mathrm{PhCCH}$ with the $\mathrm{PhCH}_{2} \mathrm{OD}$ under the conditions described in Table 2 resulted in deuterium scrambling at the $\alpha$ and $\beta$ carbons of the product 1 as detected by the ${ }^{1} \mathrm{H}$ and ${ }^{2} \mathrm{H}$ NMR spectroscopy and GC-MS (Scheme 5). The deuterium scrambling also suggests the possibility of proton exchange between benzyl alcohol and phenyl acetylene, possibly via an alkoxide intermediate.

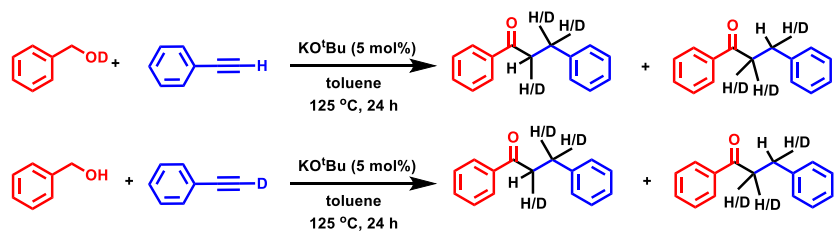

Scheme 5. Catalytic reaction of $\mathrm{PhCCD} / \mathrm{H}$ and $\mathrm{PhCH} 2 \mathrm{OD} / \mathrm{H}$.

In conclusion, we report a transition-metal free C-C bond-forming reaction of benzyl alcohols and alkynes to form $\alpha$ alkylated ketones using a catalytic amount of KO'Bu. The reaction proceeds at $125{ }^{\circ} \mathrm{C}$ and shows unusual regioselectivity. Additionally, the reaction does not produce any waste. Overall, this is a highly atom-efficient, environmentally benign and sustainable reaction. Based on our mechanistic investigations, especially the detection of a radical species from the EPR spectroscopy, we propose that the reaction proceeds through radical pathways as outlined in Scheme 4.

\section{ACKNOWLEDGMENTS}

This research was supported by the European Research Council (ERC AdG 692775). D. M. holds the Israel Matz Professorial Chair of Organic Chemistry. A.K. is thankful to the Israel Planning and Budgeting Commission (PBC) for a fellowship. T.J. thanks the Azrieli Foundation for a postdoctoral fellowship.

Keywords: Potassium tert-butoxide $\alpha$-alkylated ketone $\cdot$ radical dihydrochalcone $\bullet$ benzyl alcohol $\bullet$ alkyne

[1] (a) A. Behr, Organometallic Compounds and Homogeneous Catalysis Wiley-VCH: Weinheim, 2002; (b) F. Diederich, Stang, P. J., Metal-Catalyzed Cross-Coupling Reactions, Wiley-VCH: Weinheim, 1998; (c) G. Dyker, Ed, Handbook of C-H Transformations: Applications in Organic Synthesis, WileyVCH: Weinheim, 2005; (d) R. Jana, T. P. Pathak, M. S. Sigman, Chem. Rev. 2011, 111, 1417-1492.

[2] (a) C.-L. Sun, Z.-J. Shi, Chem. Rev. 2014, 114, 9219-9280; (b) J. P. Barham, G. Coulthard, K. J. Emery, E. Doni, F. Cumine, G. Nocera, M. P. John, L. E. A. Berlouis, T. McGuire, T. Tuttle, J. A. Murphy, J. Am. Chem. Soc. 2016, 138, $7402-7410$

[3] (a) A. A. Toutov, W.-B. Liu, K. N. Betz, A. Fedorov, B. M. Stoltz, R. H. Grubbs, Nature 2015, 518, 80; (b) S. Banerjee, Y.-F. Yang, I. D. Jenkins, Y. Liang, A. A. Toutov, W.-B. Liu, D. P. Schuman, R. H. Grubbs, B. M. Stoltz, E. H. Krenske, K. N. Houk, R. N. Zare, J. Am. Chem. Soc. 2017, 139, 6880-6887; (c) W.-B. Liu, D. P. Schuman, Y.-F. Yang, A. A. Toutov, Y. Liang, H. F. T. Klare, N. Nesnas, M. Oestreich, D. G. Blackmond, S. C. Virgil, S. Banerjee, R. N. Zare, R. H. Grubbs, K. N. Houk, B. M. Stoltz, J. Am. Chem. Soc. 2017, 139, 6867-6879. [4] (a) D. L. Boger, H. Miyauchi, W. Du, C. Hardouin, R. A. Fecik, H. Cheng, I. Hwang, M. P. Hedrick, D. Leung, O. Acevedo, C. R. W. Guimarães, W. L. Jorgensen, B. F. Cravatt, J. Med. Chem. 2005, 48, 1849-1856; (b) J. Y. Hwang, L. A. Arnold, F. Zhu, A. Kosinski, T. J. Mangano, V. Setola, B. L. Roth, R. K. Guy, J. Med. Chem. 2009, 52, 3892-3901; (c) K. Biswas, T. A. N. Peterkin, M. C. Bryan, L. Arik, S. G. Lehto, H. Sun, F.-Y. Hsieh, C. Xu, R. T. Fremeau, J. R. Allen, J. Med. Chem. 2011, 54, 7232-7246; (d) R. Perrone, F. Berardi, N. A Colabufo, E. Lacivita, M. Leopoldo, V. Tortorella, J. Med. Chem. 2003, 46, 646649; (e) C. Baskakis, V. Magrioti, N. Cotton, D. Stephens, V. ConstantinouKokotou, E. A. Dennis, G. Kokotos, J. Med. Chem. 2008, 51, 8027-8037; (f) G. H. Robertson, J. P. Clark, R. Lundin, Ind. Eng. Chem. Prod. Res. Develop. 1974 13, 125-129; (g) M. J. Matos, S. Vazquez-Rodriguez, E. Uriarte, L. Santana, Expert Opin. Ther. Pat. 2015, 25, 351-366.

[5] (a) L. Krbechek, G. E. Inglett, M. Holik, B. Dowling, R. Wagner, R. Riter, J. Agric. Food Chem. 1968, 16, 108-112; (b) H. A. B. Linke, D. E. Eveleigh, in Z. Naturforsch. B, 1975, 30, 606.

[6] (a) F. Huang, Z. Liu, Z. Yu, Angew. Chem. Int. Ed. 2016, 55, 862-875; (b) M Pena-Lopez, P. Piehl, S. Elangovan, H. Neumann, M. Beller, Angew. Chem. Int.
Ed. 2016, 55, 14967-14971; (c) S. Elangovan, J.-B. Sortias, M. Beller, C. Darcel, Angew. Chem. Int. Ed. 2015, 54, 14483-14486; (d) G. Zhang, J. Wu, H. Zeng, S. Zhang, Z. Yin, S. Zheng, Org. Lett. 2017, 19, 1080-1083; (e) S. Liao, K. Yu, Q. Li, H. Tian, Z. Zhang, X. Yu, Q. Xu, Org. Biomol. Chem. 2012, 10, 29732978

[7] (a) J. Ma, N. Wang, F. Li, Asian J. Org. Chem. 2014, 3, 940-947; (b) J. Umasish, B. Srijit, M. Sukhendu, Eur. J. Org. Chem. 2008, 2008, 5798-5804; (c) L. R. Jefferies, S. P. Cook, Tetrahedron 2014, 70, 4204-4207.

[8] (a) C. J. Evoniuk, G. dos Passos Gomes, S. P. Hill, S. Fujita, K. Hanson, I. V. Alabugin J. Am Chem Soc. 2017, 139, 16210-16221; (b) M. Pichette Drapeau, I. Fabre, L. Grimaud, I. Ciofini, T. Ollevier, M. Taillefer, Angew. Chem., Int. Ed. 2015, 54, 10587- 10591.

[9] X. Li, H. Li, C. Xu, X. Hao, Z. Xiao, 2016, CN103242372A

[10] T. Imahori, C. Hori, Y. Kondo Adv. Synth. Catal. 2004, 346, 1090-1092.

[11] J. Cuthbertson, J. D. Wilden, Tetrahedron 2015, 71, 4385-4392.

[12] (a) S. Tsunetake, N. Tetsuo, O. Makoto, Chem. Lett. 2006, 35, 824-829;(b) M. K. Barman, A. Baishya, S. Nembenna, J. Organomet. Chem. 2015, 785, 52 60 .

[13] F. Kurosawa, T. Nakano, T. Soeta, K. Endo, Y. Ukaji, J. Org. Chem. 2015 80, 5696-5703.

[14] J. P. Barham, S. E. Dalton, M. Allison, G. Nocera, A. Young, M. P. John, T. McGuire, S. Campos, T. Tuttle, J. A. Murphy, J. Am. Chem. Soc. 2018,

140, 11510-11518.

[15] H. Yi, A. Jutand, A. Lei, Chem. Commun. 2015, 51, 545-548.

[16] (a) B. Suchand, G. Satyanarayana, Eur. J. Org. Chem. 2017, 2017, 38863895; (b) D. P. Estes, J. R. Norton, S. Jockusch, W. Sattler, J. Am. Chem. Soc 2012, 134, 15512-15518

[17] (a) H.-X. Zheng, Z.-F. Xiao, C.-Z. Yao, Q.-Q. Li, X.-S. Ning, Y.-B. Kang, Y. Tang, Org. Lett. 2015, 17, 6102-6105; (b) S. Furukawa, Y. Ohno, T. Shishido, K. Teramura, T. Tanaka, ChemPhysChem 2011, 12, 2823-2830. 


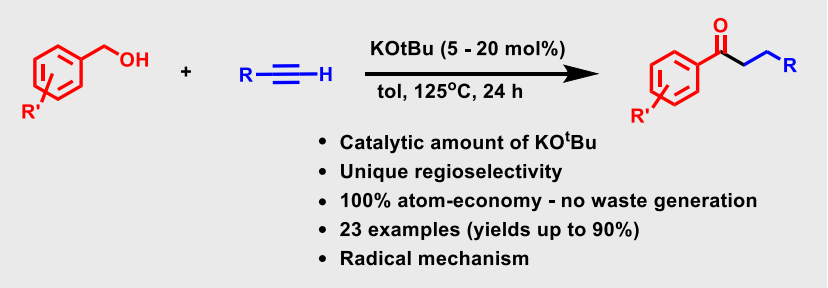

A. Kumar, T. Janes, S. Chakraborty, $P$. Daw, N. von Wolff, R. Carmieli, Y. Diskin-Posner, D. Milstein*

Page No. - Page No.

C-C Bond-Formation of Benzyl Alcohols and Alkynes Using a Catalytic Amount of KOtbu: Unusual Regioselectivity via a Radical Mechanism. 